\title{
COVID-19: A FOREST FIRE RATHER THAN A WAVE?
}

Elena Semino

As I write this piece, many countries around the world are being described as experiencing a «second wave» of the COVID-19 pandemic. For example, on 19 September 2020, the UK Prime Minister Boris Johnson said: «We are now seeing a second wave coming in. We've seen it in France, in Spain, across Europe. It's been absolutely inevitable, I'm afraid, that we would see it in this country».

Metaphors are crucial tools for communication and thinking, and can be particularly useful in public health communication. For example, the «second wave» metaphor suggests that there is renewed danger and threat from the virus, and may therefore encourage compliance with measures aimed at reducing transmission. However, all metaphors have both strengths and limitations, and the potential to be used both to enlighten and to obfuscate. The metaphor of the pandemic as a series of waves suggests that changes in the number of infections are due to the virus itself (cf. the idea that it may be seasonal), rather than the result of actions taken to slow its spread. In this sense, this metaphor is inaccurate. As Dr. Margaret Harris from the World Health Organization put it, «We are in the first wave. There is going to be one big wave». In addition, precisely because waves follow one another uncontrollably, this metaphor can be used strategically to present new increases in infection as inevitable, as in Boris Johnson's statement, and thus to deflect responsibility from governments and their policies.

As with any other complex and long-term problem, different metaphors are needed to capture different aspects of the pandemic, convey different messages, and address different audiences.

Based on the analysis of two different datasets (the \#ReframeCovid multilingual metaphor collection - an open-source repository of non-war-related language on COVID-19 - and the English Coronavirus Corpus - a multi-million-word database of news articles in English since January 2020 - I suggest that the metaphor of COVID-19 as a fire, and specifically a forest fire, is particularly apt and versatile. Forest fires are dangerous and hard to control. However, they can be controlled, with prompt and appropriate action. They can even be prevented, by looking after the land properly, protecting the environment, and educating citizens to behave responsibly. Indeed, forest fire metaphors for COVID-19 have been used since the start of the pandemic for multiple purposes, including to: convey danger and urgency (e.g., COVID-19 as a «forest fire that may not slow down»); distinguish between different phases of the pandemic (e.g., «a fire raging» vs. «embers» that must be stopped from causing a new fire); explain how contagion happens and the role of individuals within that (e.g., people as trees in a forest catching fire one after the other, or as breathing out «invisible embers»); justify measures for reducing contagion (e.g., social distancing as «fire lines» in a forest); connect the pandemic with health inequalities (e.g., pointing out that, like a fire, COVID-19 spreads more easily when people live in overcrowded conditions); and outline post-pandemic futures (e.g., when an Italian commentator pointed out that everyone has to contribute to the reclamation of the soil - bonifica del terreno - after the end of the pandemic, to prevent future ones).

Of course, no metaphor is suitable for all purposes or all audiences. For example, the metaphor of people as trees in a forest fire does not easily account for asymptomatic transmission. And the use of forest fire metaphors may be inappropriate in parts of the world that have been dramatically affected by literal fires, such as some parts of Australia in 2019-2020. However, a well-informed and context-sensitive approach to metaphor selection can be an important and effective part of public health messaging.

ELENA SEMINO. Professor at the Department of Linguistics and English Language of Lancaster University (UK) and Director of the ESRC Centre for Corpus Approaches to Social Science. She has over a hundred publications and is the author of books such as Metaphor in discourse (2008), as well as the co-author of others like Metaphor, cancer and the end of life: A corpus based study (2018) and The Routledge handbook of metaphor and language (2017). 